\title{
American health care reformers in search of a second wind
}

Published at www.cmaj.ca on Feb. 5

$\mathrm{M}$ ere weeks ago, it was all but impossible to escape the din of the great health reform campaign in Washington. Now it's all you can do to find its pulse.

Recovering from a stunning setback in their political fortunes and legislative prospects, Democrats have practically gone underground on the issue. Simply put, leaders of Congress don't know what to do next to advance the cause. But they know they want to do something.

The way forward on what had been President Barack Obama's signature domestic initiative became much less clear when Republican Scott Brown won a Senate seat Jan. 19 to replace the late liberal icon Ted Kennedy in Massachusetts, one of the most Democratic states in the nation.

The upset caught the political establishment by surprise just as congressional leaders were in the final stages of negotiations to enact the most far-reaching expansion of health care coverage in generations. The Senate and the House of Representatives had both passed bills, with sticky differences to reconcile (CMAJ 2010. DOI:10.1503/cmaj.1093148). Legislators had hoped to tie it all up by Obama's Jan. 27 State of the Union address.

Then literally overnight, Democrats snatched gridlock from the jaws of victory.

In addition to losing the 60-vote Senate majority needed to advance bills past Republican delaying tactics, Democrats lost their nerve, at least in the first days of the new order. From Obama on down, they read the Massachusetts election as a nationwide commandment to switch the focus to jobs. Many of them saw it too, as a repudiation of their complex, backroom-dealing enterprise behind the legislation.

But health reform still has a heartbeat.

"I won't walk away from these efforts," Obama declared early in February in New Hampshire. "I won't walk

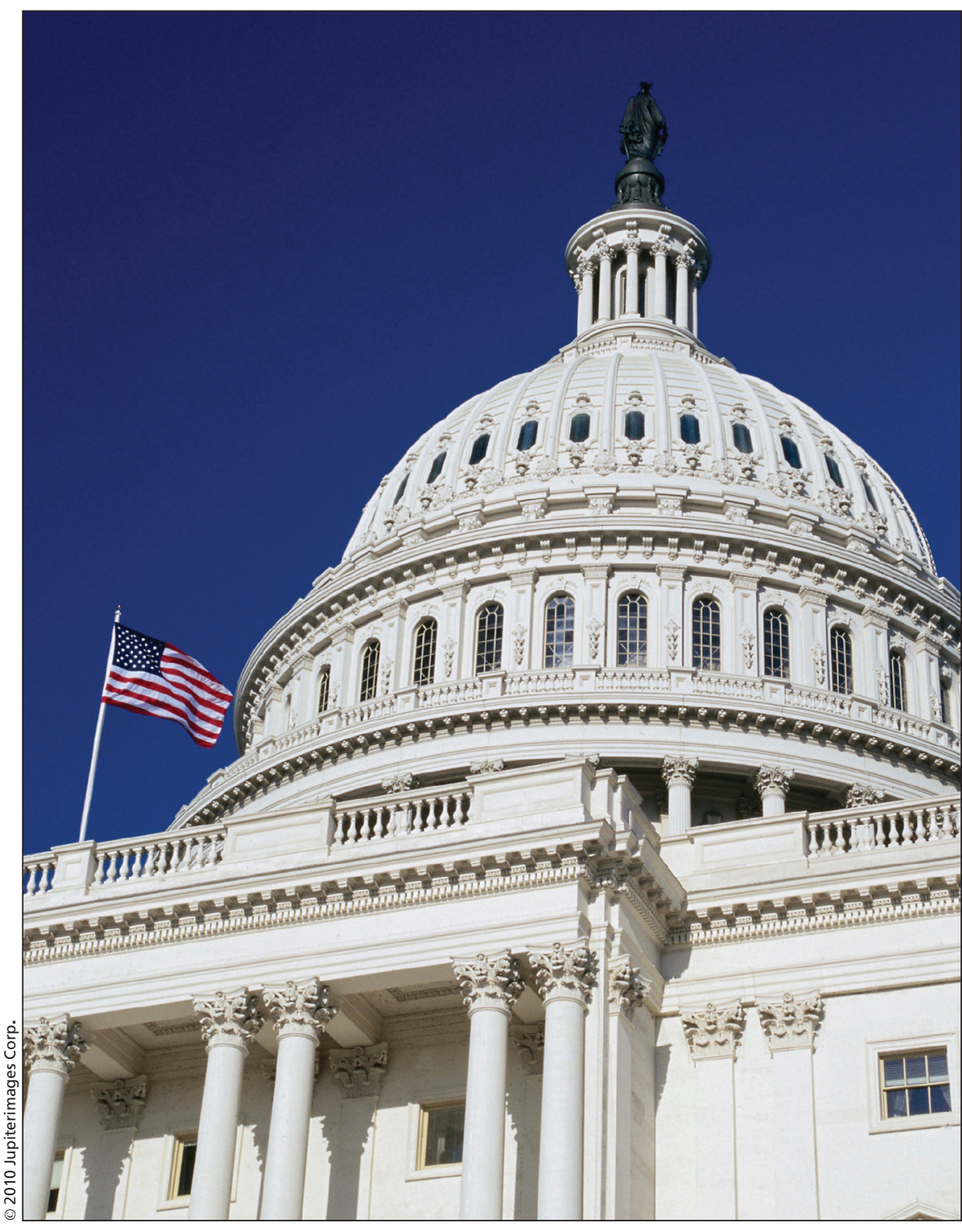

Talks of health care reform have recently grown quiet in Washington, DC, but United States President Barack Obama has promised not to walk away from the issue.

away from these people."

Those people are the more than 30 million uninsured as well as the millions whose insurance costs have been going through the roof.

Obama's remarks were tucked into a pitch for small-business tax breaks to spur employment, the new push. Despite changing the subject, leaders are quietly exploring options to salvage a nearly US\$1-trillion legislative pack- age aimed at bringing affordable health insurance to $95 \%$ of Americans.

A look at the leading options and the pros and cons being weighed by negotiators:

\section{Going for broke:}

A parliamentary manoeuvre called reconciliation would enable the package to be adopted with a simple majority of 51 votes in the Senate instead of the now- 
elusive 60 . The Senate has already passed a health bill but House Democrats refuse to rubber stamp it. Lawmakers have begun drafting a separate bill that would resolve differences between the two chambers, with a tentative goal of passing it with a simple majority.

Pros: Reconciliation is the most direct path to preserving the bulk of reforms and overcoming Republicans' solid opposition.

Cons: Many Democrats, already bracing for losses in House and Senate elections in November, fear even greater consequences if they ram through a health package with higher taxes and a requirement for most Americans to get health insurance at a time of $10 \%$ unemployment.

\section{Cherry picking:}

Legislators have considered passing only the most popular parts. Efforts are already under way to strip health insurance companies of their exemption from antitrust laws. Even broader support exists for prohibiting insurers from denying coverage to people with pre-existing illness.

Pros: Democrats would win some Republican votes for certain measures.

Cons: Legislators say it won't work to eliminate widely despised insurance practices without the subsidies, taxes and insurance mandate in the package. If people could wait until they get sick before they buy insurance, premiums would skyrocket for everyone.

"So there are some things that sound easy, but you might as well send somebody a get well card because they don't have any more impact, except maybe they make you feel good for the moment," House Speaker Nancy Pelosi told reporters. "Maybe a get well card might be more effective, as a matter of fact, because it's sincere."

\section{Starting over:}

Democrats could begin anew with a more concerted effort to involve Republicans.

Pros: Democrats could set aside a contentious issue before the midterm elections and come back to it later.

Cons: Few believe the two parties would join in the painstaking process of reinventing reforms when jobs demand attention.

After Bill Clinton lost the fight to overhaul health care in 1994, Democrats dropped the subject for a decade. History teaches that once health reform is set aside, it does not soon return. Cal Woodward, Washington, DC

DOI:10.1503/cmaj.109-3175 